\title{
Research \\ Communication in Natural Resource Management: Agreement between and Disagreement within Stakeholder Groups
}

\author{
Wouter de Nooy $^{1}$
}

\begin{abstract}
Communication among stakeholders is commonly held to improve agreement on facts and management goals. Results from statistical network analyses of six natural resource management systems indicate that the effects of communication depend on context. If communication affects stakeholder knowledge and values, it fosters agreement between stakeholder groups but it results in more disagreement within stakeholder groups. In addition, more centralized communication networks have more disagreement, especially within stakeholder groups, while co-management systems have more disagreement between stakeholder groups. The results may reflect communication effects but also selection effects: the propensity of stakeholders or management systems to establish communication ties between participants with dissimilar knowledge and values. In addition, the results may be linked to different phases in the management process. The conclusion includes a reflection on the need for further research to address these possibilities.
\end{abstract}

Key Words: communication networks; interpersonal communication; network autocorrelation; natural resource management; stakeholder groups

\section{INTRODUCTION}

Management of natural resources involves several types of stakeholders who differ with respect to knowledge and problem definitions, and hence they pursue different management solutions. For some time, it has been argued that all stakeholders need to be equally involved in the management process for effective natural resource management (e.g., Jentoft et al. 1998). Communication among stakeholders is assumed to be critical in this process. It is essential to social learning (Tompkins and Adger 2004, Crona and Hubacek 2010), which improves the evaluation of management outcomes (Andersson 2006). It helps to develop a holistic view of the problem (Dreyer and Renn 2011) because stakeholders learn to understand each other's actions (Blumenthal and Jannink 2000). It fosters trust and consensus, which are necessary to reach agreement on common rules for managing natural resources (Schneider et al. 2003). As Crona and Bodin (2006) clearly state, the exchange of information and knowledge among stakeholder groups is fundamental to the successful management of natural resources.

In the natural resource management literature, the relevance of communication to cooperation has mainly been based on general theories and formal models of cooperation (e.g., Axelrod 1984, Ostrom 1990). Of late, investigators of natural resource management have started using theories and models from social network analysis to argue for the importance of communication and network structure (Newman and Dale 2005, Bodin et al. 2006, Chang et al. 2012). Recently, for example, a book and a special issue appeared on this topic (Crona and Hubacek 2010, Bodin and Prell 2011). Network analysis promises to be a productive approach because interpersonal communication is a natural and appealing example of a social network relation.

Network analysis in natural resource management focuses on several structural characteristics of the overall communication network, two of which are particularly relevant to the present paper: centralization and network heterogeneity. Network centralization measures the extent to which a smaller set of actors are involved (directly or indirectly) in a larger share of network ties. On the one hand, centralization is hypothesized to enhance effective communication and collective learning; on the other hand network centralization may also have negative effects on deliberation (Newig et al. 2010). The effects of centralization may depend on network heterogeneity, that is, the proportion of ties between actors with different characteristics or group affiliations; adaptive management processes seem to require both centralization and network heterogeneity (Sandström and Rova 2010). By itself network heterogeneity is important to co-management because communication among groups (bridging ties) implies the confrontation of different knowledge, opinions, and interests that is probably required for collective action (e.g., Crona and Bodin 2006, Newman and Dale 2007).

The focus of social network analysis is not exclusively on overall network structure. In addition, it addresses the causes and consequences of individual network ties. Consequences of network ties for attributes and behavior of network members are summarized in the theory of social influence (Friedkin and Johnsen 1990, Friedkin 1998), which is also known as social contagion theory (Monge and Contractor 2003). In essence, this theory states that people tend to adapt their behaviors,

\footnotetext{
${ }^{1}$ Amsterdam School of Communication Research (ASCoR), University of Amsterdam
} 
opinions, and values to those of their network contacts. Adaptation is more likely if the social tie between persons is stronger. The theory is based on several classic insights from social psychology (Borgatti and Foster 2003), notably theories of social comparison (Festinger 1954), cognitive dissonance (Festinger 1957), and the contact hypothesis for intergroup relations (Allport 1954). Applied to communication networks within natural resource management systems, the theories predict that communication partners are more likely to have similar knowledge, opinions, and values (Prell et al. 2009).

Scientists have developed and implemented models and procedures that enhance the participation of stakeholders aiming at collaborative management of the natural resource (for an overview, see Blumenthal and Jannink 2000). Increasingly, management systems involve stakeholder representatives in scientific modeling of natural resources in addition to policy planning and execution (e.g., Mackinson et al. 2011, Röckmann et al. 2012). Co-management allows stakeholder representatives to share knowledge, understand different standpoints, and converge on rules for collective action, which increases the legitimacy and effectiveness of management decisions. In co-management systems, then, stakeholders are more likely to adapt their knowledge and opinions to those of their communication partners.

The assumed effects of communication networks have hardly been tested rigorously for natural resource management, Prell et al. (2010) being a notable exception. The effects should, however, not be taken for granted. The social-psychological literature, for example, suggests that communication does not always lead to agreement. The effects of communication on the sharing of knowledge and values are moderated by contextual factors among which group affiliations play a major role; for example, social comparison theory predicts contrasting - taking opposite positions-rather than agreement if a peer belongs to another group (outgroup) or has different personal characteristics (Suls et al. 2002).

Within natural resource management systems, stakeholder groups are likely to provide strong group identities that may be in the way of assimilating knowledge and values among communication partners (Mushove and Vogel 2005, Newman and Dale 2007). In a similar vein, national identity may play a role in international management systems. Therefore, it is important to reckon with disagreement rather than agreement as a result of communication among members of different stakeholder groups or nationalities.

This paper aims to show that the effect of interpersonal communication on agreement among stakeholders in natural resource management depends on context: stakeholder group, overall network structure, and type of management system (national versus international, with versus without comanagement). It attempts to answer five research questions:
RQ1 - Do knowledge and values vary among stakeholder groups?

RQ2 - Does interpersonal communication increase agreement on knowledge and values?

RQ3 - Does communication within stakeholder groups have the same effect on knowledge and values as communication between stakeholder groups?

RQ4 - Do the effects of communication on knowledge and values depend on the structure of the communication network?

RQ5 - Do the effects of communication on knowledge and values depend on the type of management system?

\section{METHODS}

The data originated from an international research project funded by the European Union: JAKFISH, Judgement and Knowledge in Fisheries Involving Stakeholders (Pastoors et al. 2012). The project included a comparative research on approaches to handling complexity and uncertainty in fisheries management decision-making both within and outside Europe. The objective was to identify the most effective institutional forms, practices, and techniques for developing science-based policies and marine management measures. To compare institutional forms, two management systems were selected that include stakeholders at high levels of sciencebased policy making (Australia, northern prawn fishery; USA, New England groundfish), that is, co-management systems, and four cases without co-management (Estonia, Riga herring fishery; international, Baltic salmon fishery; Finland, Baltic salmon fishery; international, Mediterranean swordfish fishery) (Goldsborough et al. 2011).

In our study, the management system types determined by the JAKFISH study (co-management and no co-management) are retained. Within these two systems, multiple types of stakeholders exist: fishermen-industrial and possibly recreational-government officials, scientists, ecologists from NGOs, and so on. Based on studies of policy documents and open interviews ( 7 to 19 per management system), the relevant stakeholder groups were identified for each management system and the main participants were selected by means of snowballing, yielding from 23 up to 56 stakeholders per system, including the interviewed experts.

\section{Survey of stakeholder knowledge and values}

Sciences tend to vary with respect to perspectives, core problems, and proposed solutions in fishery management; for example, economists stress efficiency matters and the problem of the commons, which would require individual transferable quotas, whereas biologists focus on the problem of stock renewal, arguing for marine protected areas, and sociologists 
point to the problems of fisher communities, which would be solved by community-based management (Degnbol et al. 2006). Because each perspective is typically more in line with the interests of one stakeholder group than another, problem definitions, proposed solutions, and even economic or biological facts are contested among stakeholders. From policy documents on management of the selected fish species and open interviews, sixteen statements were constructed that address contested scientific facts (knowledge statements, e.g., "It is impossible to model the impact of rainfall on banana prawns because this impact is different in different areas.") and sixteen statements representing contested positions on management problems and solutions (value statements, e.g., "Once a prawn has bred there should be no restrictions on a fisherman's ability to catch that prawn.”).

An online survey was administered to the selected stakeholders with response rates varying from roughly onethird (Mediterranean swordfish) to four out of five (Gulf of Riga herring, Finland Baltic Sea salmon). Responses to the sixteen knowledge and sixteen value statements were elicited by means of the Q-sort technique (Brown 1986, Brown 1993). Each stakeholder sorted statements into sets ranging from most certainly false to most certainly true (knowledge) or disagree most to agree most (values). This technique yielded a forced (more or less normal) distribution for the answers to each set of sixteen statements for each respondent with values ranging from -3 to +3 .

The online survey also presented each stakeholder with a list containing the names of the other stakeholders and the question to select the five persons with whom he or she discusses fishery management issues most frequently. From the answers a communication network was constructed for each case study. Figures 1 and 2 present examples of communication networks. Node colors and pictograms indicate stakeholder groups and node size represents the number of times a stakeholder was chosen as a frequent discussion partner. The Australian prawn stakeholders communication network (Fig. 1) has relatively low network heterogeneity: stakeholders choose discussion partners among members of their own stakeholder group (dashed arcs) relatively often, which is especially true for the fishers. In contrast, the communication network for the stakeholders in the Estonian Gulf of Riga herring case (Fig. 2 ) is much more heterogeneous, having more communication links between members of different stakeholder groups (solid arcs).

\section{Network autocorrelation}

Research Questions 2 to 5 addressed the effects of communication on stakeholders' knowledge and values. With cross-sectional network data, the network autocorrelation model is the most appropriate technique to test whether a person's values and knowledge depend on the values and knowledge of the persons he or she is linked to in the communication network. A network autocorrelation model is a linear regression model, predicting a characteristic of a person from the same characteristic of its network contacts while controlling for effects of other characteristics. It is similar to a spatial autocorrelation model, explaining properties of regions from properties of neighboring regions. It extends bivariate measures of network correlation, such as Geary's C used by Prell et al. (2010), to a multivariate model. This extension is important because it allows distinction between competing effects, e.g., between the effects of stakeholder type and communication partners.

Fig. 1. Sociogram of the discussion network with stakeholder type, Australian Northern Prawn Fishery (node size represents number of nominations, within-group ties are dashed).

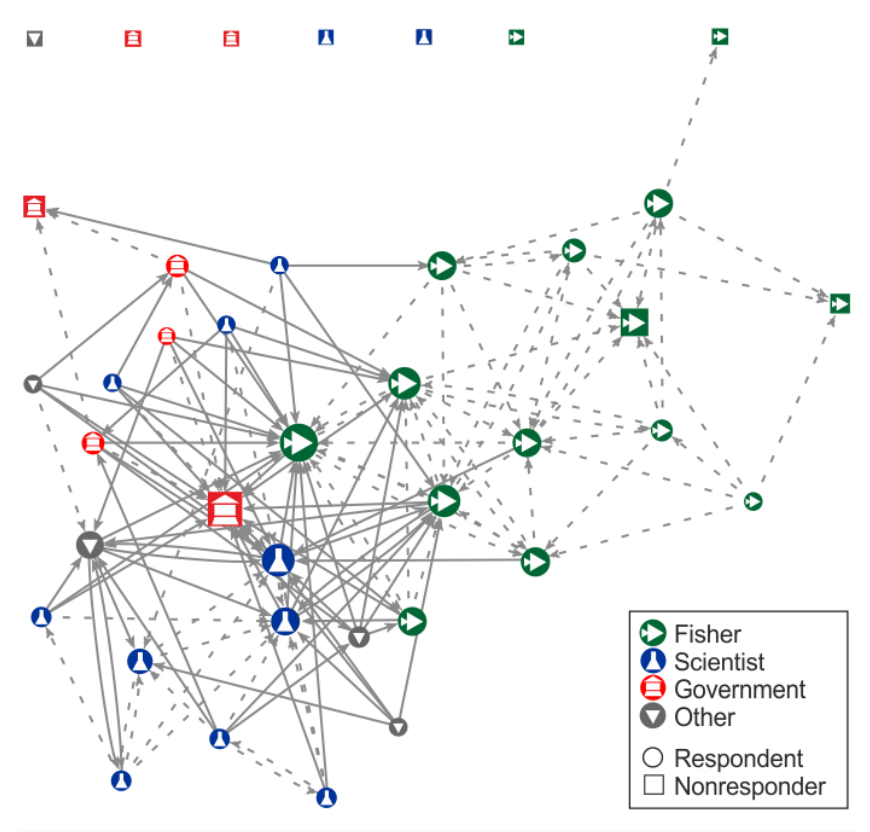

There are different types of network autocorrelation models (Doreian 1980). We applied a dependent variable autocorrelation model rather than a disturbances autocorrelation model because the former model assumes that persons change their values and knowledge towards or away from the values and knowledge of their discussion partners, which is relevant here. A dependent variable autocorrelation model includes the network as a weight matrix (Leenders 2002). The raw dichotomous adjacency matrix is used as the weight matrix rather than a normalized matrix. This implies that each stakeholder is equally influenced by all of its five frequent communication partners. Note that tests weighing for communication intensity produced the same results, so a more complicated weight matrix is not necessary. 
Fig. 2. Sociogram of the discussion network with stakeholder type, Estonian Gulf of Riga Herring (node size represents number of nominations, within-group ties are dashed).

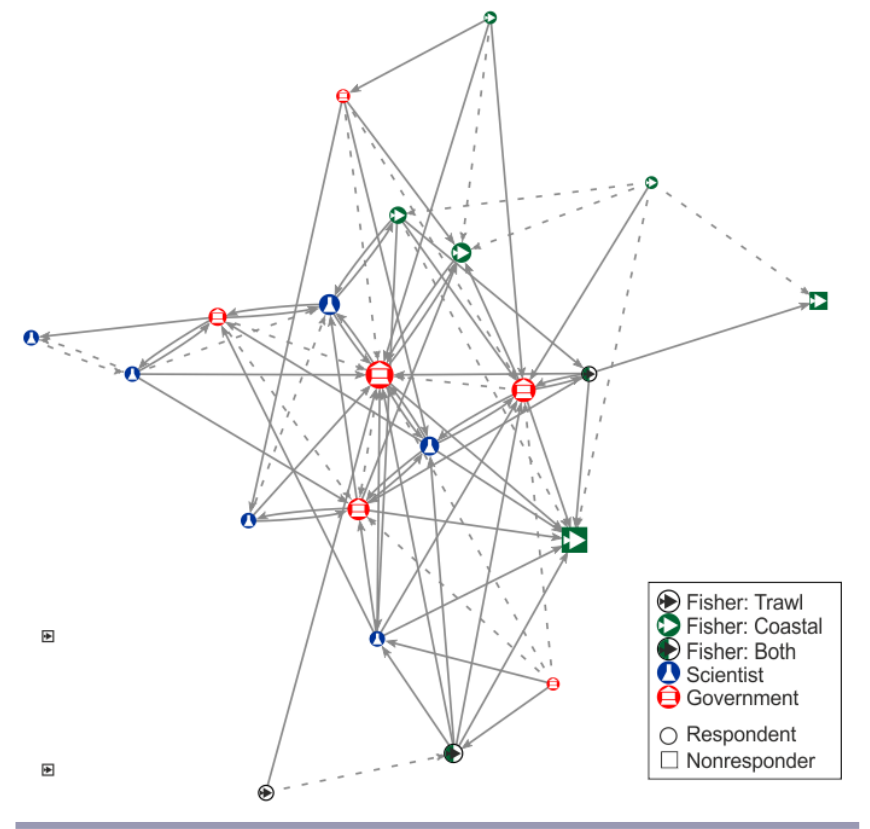

The weight matrix $(\mathbf{W})$ is multiplied by the dependent variable vector $(\mathbf{Y})$ to obtain a predictor with the sum of the scores on the dependent variable of a stakeholder's network contacts. If this sum is systematically associated with the stakeholder's score on a knowledge statement or value, the autocorrelation effect is significantly different from zero. A positive parameter value signals that stakeholders' knowledge or value is more similar to their contacts' knowledge or value (agreement) than to the knowledge and value of stakeholders with whom they do not communicate directly. A negative parameter value shows a tendency to disagree more with communication partners than with other stakeholders in the network.

We should note two complications with network autocorrelation models. First, stakeholders who did not fill out the survey (nonresponders) were not included in the estimation of autocorrelation effects because their values and knowledge scores were not known. Second, recent simulation research has shown that the network autocorrelation model tends to underestimate autocorrelation effects (Mizruchi and Neuman 2008). Estimated effects are systematically biased in a negative direction, so true positive effects may be estimated as absent or even as negative effects while true negative effects may be estimated stronger than they really are. However, for low-density networks, such as the ones investigated here, the bias is less marked and only occurs in the case of positive autocorrelation, which may be underestimated. As a consequence, positive effects that are marginally significant $(0.05 \leq p<0.10)$ are treated as if they are significant at the $5 \%$ level.

Finally, the network autocorrelation model does not establish a causal direction. In the data used here, communication took place before knowledge and values were measured; stakeholders nominated persons with whom they had communicated about fishery management at the time their knowledge and values were queried. With cross-sectional data, however, one cannot be sure about the causal order. Stakeholders may have had the knowledge and values already before they started to communicate. If this is the case, the structure of the communication network is the result rather than the cause of knowledge and value differences, which is known as the selection effect (Robins et al. 2001) or homophily (McPherson et al. 2001). In the interpretation of network autocorrelation effects, this duality is taken into account.

\section{Analysis 1: effects of communication network and stakeholder group}

The first set of analyses tested effects of stakeholder group (RQ1) and communication ties (RQ2) on stakeholders' knowledge and values. For each knowledge and value statement, stakeholders' responses $(\mathbf{Y})$ were regressed on the overall communication network $\left(\mathrm{W}_{\text {overall }}\right)$ and dummy ( 1 or 0$)$ variables representing general stakeholder types $(\mathbf{X})$ : (industrial) fishery, science, government, and other, containing, for instance, ecological NGOs and recreational fishery. Fishery was the reference category in each network autocorrelation model. Equation (1) summarizes this network autocorrelation model in matrix notation. The network autocorrelation parameter $\rho$ expresses the sign (positive or negative) and strength (absolute value) of the communication effect. It is estimated while controlling for stakeholder type just as the effect of stakeholder type $(\beta)$ is controlled for communication effects, so the two effects are not confounded.

\section{Model 1a:}

$$
\mathbf{Y}=\alpha+\rho \mathbf{W}_{\text {overall }} \mathbf{Y}+\mathbf{X} \boldsymbol{\beta}+\varepsilon \quad \text { with } \varepsilon \sim N\left(0, \sigma^{2}\right)
$$

In addition, the effects of ingroup versus outgroup communication were compared (RQ3). To this end, the overall communication network was split into a network of communication ties within stakeholder groups and a network of communication ties among stakeholder groups. Note that the network was split according to the original stakeholder groups for each management system and not according to the four general categories used as independent variables $(\mathbf{X})$ in the model. The number of stakeholder groups varied across management systems. Equation (2) is the autocorrelation model in matrix notation.

$$
\begin{aligned}
& \text { Model 1b: } \\
& \begin{aligned}
\mathbf{Y}= & \alpha+\rho_{\text {ingroup }} \mathbf{W}_{\text {ingroup }} \mathbf{Y}+\rho_{\text {outgroup }} \mathbf{W}_{\text {outgroup }} \mathbf{Y} \\
& +\mathbf{X} \boldsymbol{\beta}+\varepsilon \text { with } \varepsilon \sim N\left(0, \sigma^{2}\right)
\end{aligned}
\end{aligned}
$$


Table 1. Management systems: overview.

\begin{tabular}{lcccc}
\hline \hline Management system & $\begin{array}{c}\text { Network } \\
\text { centralization }\end{array}$ & $\begin{array}{c}\text { Network } \\
\text { heterogeneity }\end{array}$ & Co-management & Scope \\
\hline Australia, northern prawn & 0.39 & 0.48 & Yes & National \\
International, Baltic salmon & 0.29 & 0.31 & No & International \\
Finland, Baltic salmon & 0.37 & 0.66 & No & National \\
Estonia, Riga herring & 0.50 & 0.75 & No & International \\
Mediterranean, swordfish & 0.22 & 0.56 & Yes & National \\
USA, New England groundfish & 0.24 & 0.49 & &
\end{tabular}

The models were estimated with the lnam routine using the default Broyden, Fletcher, Goldfarb, and Shanno (BFGS) estimation method in Carter Butts' sna package available in R (Butts 2006). Descriptive network analysis and network visualization were done with Pajek software (de Nooy et al. 2011).

\section{Analysis 2: effects of the management system}

In the first set of analyses, described in the previous subsection, the network autocorrelation effect was estimated for each knowledge and value statement separately. The estimates indicated whether communication partners agree (positive network autocorrelation coefficient) or disagree (negative network autocorrelation coefficient) on this statement and the extent to which they agree or disagree (the absolute value of the coefficient $\rho$ ).

The second set of analyses assessed whether the type of management system is consequential to agreement or disagreement among communication partners. To this end, network autocorrelation effects for the statements were compared across the six management systems. At this point, each statement represented an observation and the dependent variable was the network autocorrelation effect for this statement. The first set of analyses yields three different autocorrelation effects for each statement (overall, ingroup, and outgroup), so three versions of the model must be estimated.

To answer RQ4, two structural characteristics of the overall communication network were calculated and used as independent variables: in degree centralization (Wasserman and Faust 1994) and network heterogeneity, simply calculated as the percentage of outgroup ties in the network. For RQ5, two properties of the management system were included as predictors: a dichotomy indicating whether the system implements co-management $(1=$ yes, $0=$ no $)$ according to the design of the study, and a dichotomy distinguishing between international management systems (1) and national or regional systems (0). Table 1 describes the predictors at the management system level.

Statements were clustered within management systems, creating dependencies among observations within management systems. A multilevel model with 192 statements at the lowest level and 6 management systems at the second level compensates for the dependencies. Equation 3 specifies the multilevel model in matrix format: $\alpha$ is the fixed constant, $\delta_{j}$ represents the variance in the (random) intercepts of management systems $(j), \mathbf{X}_{\mathrm{j}}$ is a matrix of management system characteristics by statements, and $\beta$ is a vector of estimated effects of these characteristics. The dependent variable $\rho$ is the overall, ingroup, or outgroup network autocorrelation coefficient estimated for the statement in the first set of analyses (Models 1a and 1b). RIGLS estimation was used in MLwiN software (Rasbash et al. 2004).

$$
\begin{aligned}
& \text { Model 2: } \\
& \rho=\alpha+\delta_{\mathrm{j}}+\mathbf{X}_{\mathrm{j}} \boldsymbol{\beta}+\varepsilon \\
& \text { with } \varepsilon \sim N\left(0, \sigma^{2}\right) \text { and } \delta_{\mathrm{j}} \sim N\left(0,{\sigma_{\mathrm{j}}}^{2}\right)
\end{aligned}
$$

\section{RESULTS}

\begin{tabular}{|c|c|c|c|}
\hline & Model 1a & Model $1 \mathrm{~b}$ & Model 2 \\
\hline Goal & $\begin{array}{l}\text { Effects of group } \\
\text { versus } \\
\text { communication }\end{array}$ & $\begin{array}{l}\text { Effects of group } \\
\text { and ingroup versus } \\
\text { outgroup } \\
\text { communication }\end{array}$ & $\begin{array}{l}\text { Determinants of communication } \\
\text { network effects }\end{array}$ \\
\hline Type & \multicolumn{2}{|c|}{ Network autocorrelation model } & Multilevel model \\
\hline Unit of analysis & \multicolumn{2}{|c|}{$\begin{array}{l}\text { Stakeholder }(N=19 \ldots 47=\text { number of } \\
\text { responders per system })\end{array}$} & $\begin{array}{l}\text { First level: statement }(N=192) \\
\text { Second level: system }(N=6)\end{array}$ \\
\hline $\begin{array}{l}\text { Dependent } \\
\text { variable }\end{array}$ & \multicolumn{2}{|c|}{ - Response to statement } & $\begin{array}{l}\text { - Overall network } \\
\text { autocorrelation } \\
\text { - Ingroup network } \\
\text { autocorrelation } \\
\text { - Outgroup network } \\
\text { autocorrelation }\end{array}$ \\
\hline $\begin{array}{l}\text { Independent } \\
\text { variables } \\
\text { (Predictors) }\end{array}$ & $\begin{array}{l}\text { - Stakeholder } \\
\text { group } \\
\text { - Overall network } \\
\text { (autocorrelation) }\end{array}$ & $\begin{array}{l}\text { - Stakeholder } \\
\text { group } \\
\text { - Ingroup network } \\
\text { (autocorrelation) } \\
\text { - Outgroup } \\
\text { network } \\
\text { (autocorrelation) }\end{array}$ & $\begin{array}{l}\text { System: } \\
\text { - International }(\text { yes }=1 / \mathrm{no}=0) \\
- \text { Co-management } \\
(\text { yes }=1 / \text { no }=0) \\
\text { - Network heterogeneity } \\
\text { - Network centralization }\end{array}$ \\
\hline $\begin{array}{l}\text { \# of times } \\
\text { estimated }\end{array}$ & \multicolumn{2}{|c|}{$\begin{array}{l}192 \text { (One for each statement: } 32 \\
\text { statements for each of } 6 \text { systems) }\end{array}$} & $\begin{array}{l}3 \text { (One for each dependent } \\
\text { variable) }\end{array}$ \\
\hline
\end{tabular}

Fig. 3 summarizes the models that were estimated.

Fig. 3. Overview of the analyses. 


\section{Model 1}

The network autocorrelation models (Models 1a and 1b) were estimated separately for each statement. Table 2 depicts the results for one value statement (about closing coastal fishing during spring spawning concentrations) in the Estonian case study. Let us have a close look at this example before we summarize results for all statements.

Table 2. Network autocorrelation results for one statement: unstandardized regression coefficients and $p$ values. ${ }^{\dagger}$

\begin{tabular}{|c|c|c|c|c|}
\hline \multirow{2}{*}{ Parameter } & \multicolumn{2}{|c|}{ Model 1a } & \multicolumn{2}{|c|}{ Model 1b } \\
\hline & $\mathrm{b}$ & $\mathrm{p}$ & $\mathrm{b}$ & $\mathrm{p}$ \\
\hline $\begin{array}{l}\text { Constant } \\
\text { Stakeholder } \\
\text { group } \neq\end{array}$ & $-2.23 * * *$ & 0.000 & $-2.72 * * *$ & 0.000 \\
\hline Science & 0.25 & 0.670 & 0.47 & 0.336 \\
\hline Government & 1.17 & 0.091 & $1.97 * *$ & 0.002 \\
\hline Other & 0.96 & 0.235 & 1.16 & 0.082 \\
\hline \multicolumn{5}{|l|}{ Rho } \\
\hline Overall & -0.09 & 0.359 & & \\
\hline Ingroup & & & $-0.48 * *$ & 0.001 \\
\hline Outgroup & & & -0.04 & 0.649 \\
\hline
\end{tabular}

The effects of stakeholder group on the responder's value score were estimated with three dummy variables, each representing one stakeholder group. Fisher, the fourth stakeholder group, is the reference category, so we may conclude that governmental representatives agreed with the value more (on average they score 1.96 higher) than fishers if we control for ingroup and outgroup network autocorrelation (Model 1b). Note that comparison of results across management systems requires uniform stakeholder categories, so the original stakeholder types (Fig. 2) are now grouped into four main categories.

The overall communication network had a negative predictive effect ( $\rho=-0.09$, Model 1a), which is not significant, while the predictive effect was negative and significant for ingroup communication $(\rho=-0.48$, Model $1 b)$. Stakeholders tended to communicate with members of their own group with whom they disagree rather than agree on this value statement, while controlling for differences between the four main stakeholder groups.

This example illustrates that negative ingroup network autocorrelation does not necessarily mean that stakeholders agree more with members of other groups than with members of their own group. Due to the large overall difference in agreement between fishers and government regarding this statement, a fisher's opinion probably resembles other fishers' opinions more than the opinions of government representatives even when their ingroup discussion partners are the ones with whom they disagree rather than agree. This caveat also applies to the interpretation of positive network autocorrelation and overall or outgroup network autocorrelation effects.

Rather than present tables for all 192 statements, we summarized the sign and significance of the network autocorrelation effects $\left(\rho, \rho_{\text {in }}\right.$, and $\left.\rho_{\text {out }}\right)$. Overall, positive autocorrelation was found more or less as often $(47 \%)$ as negative autocorrelation $(50 \%)$. Not all statements had statistically significant network autocorrelation: fifteen statements displayed significant agreement among discussion partners $(p<0.10)$ while fourteen statements had significant negative autocorrelation $(p<0.05)$, that is, a tendency to disagree. This amounted to $15 \%$ of all statements, which is triple the number of significant results expected by chance (5\% Type I Error rate on 192 statements; note that the significance of positive effects was underestimated). Fig. 4 shows that significant positive autocorrelation occurred more often with outgroup communication partners while significant negative autocorrelation happens more often with ingroup communication partners.

Table 3 summarizes the effects of stakeholder group affiliation on values and knowledge. There were significant differences between fishers and at least one other stakeholder group for 20 to $31 \%$ of the statements. Stakeholder groups did not differ on all statements but the number of statements that they differed on is clearly higher than the number predicted by chance if there were no differences (5\%, or $1 \%$ Type I Error).

\section{Model 2}

Finally, Table 4 presents the multilevel regression models that predicted the overall, ingroup, and outgroup autocorrelation effects (Model 2). In none of the three models were the random intercepts for management system significant, indicating that there was no substantial variation in autocorrelation among the systems that was not accounted for by the management system characteristics included in the model. In all three instances, international management systems had on average lower, more negative autocorrelation than the national management systems. Fig. 4 shows that this was due to the Mediterranean swordfish case because the other international case-international, Baltic salmon-has relatively positive autocorrelation estimates.

More centralized networks had on average lower or more negative autocorrelation. This effect did not apply, however, to outgroup communication ties. In contrast, the only significant effect of co-management systems appeared for outgroup communication but this effect was negative. Communication partners from different stakeholder groups on average agreed a little bit less $(-0.05)$ if they were part of a co-management system than if they belonged to a system without co-management. 
Table 3. Statements with significant differences among stakeholder groups.

\begin{tabular}{lccc}
\hline \hline Model & \multicolumn{2}{c}{ Fisher } \\
\cline { 2 - 4 } & $\begin{array}{c}\text { Science } \\
(\%)\end{array}$ & $\begin{array}{c}\text { Government } \\
(\%)\end{array}$ & $\begin{array}{c}\text { Other } \\
(\%)\end{array}$ \\
\hline Model 1a & & & \\
$0.01 \leq p<0.05$ & 10.4 & 10.9 & 11.5 \\
$p<0.01$ & 12.0 & 11.5 & 19.8 \\
Model 1b & & & \\
$0.01 \leq p<0.05$ & 9.4 & 7.8 & 12.0 \\
$p<0.01$ & 13.0 & 12.5 & 19.3 \\
$N$ & 192 & 192 & 192 \\
\hline
\end{tabular}

\section{DISCUSSION}

For about a quarter of all statements, at least two stakeholder groups had significantly different scores, so we may conclude that part of the knowledge and values vary between stakeholder groups (RQ1). Significant differences occurred for values as frequently as for knowledge but they were unevenly spread across management systems. The national and international Baltic salmon systems, for example, showed relatively many differences between fishers and other stakeholder groups, suggesting weaker consensus. In contrast, knowledge differences among stakeholder groups were relatively rare in the Australian, Riga, and New England management systems. This seems to indicate that the dissemination of knowledge among stakeholders has made more progress here.

To contextualize the effects of communication on stakeholders' knowledge and values, we must first assess whether communication has an effect (RQ2). If communication is effective, stakeholders' knowledge and opinions should resemble those of their communication partners yielding a positive network autocorrelation coefficient. In controlling for average differences between stakeholder groups, only part of the statements showed significant network autocorrelation. A majority of statements did not show a tendency to agree or disagree with communication partners. If communication alters knowledge and values, it did not do so for all statements, which is in line with results in previous research (Prell et al. 2009).

Network autocorrelation appeared to be negative just as well as positive, which is a new result because Prell et al. (2010) found only positive network autocorrelation. The answer to RQ2 is equivocal: communication may increase agreement as well as disagreement on knowledge and values. This result further presses the need to contextualize communication effects. However, it also directs our attention to the competing interpretation of network autocorrelation, viz., the selection of communication partners as a result of (dis)similar knowledge and values. Perhaps management systems force stakeholders to communicate with people who have different knowledge and values even if they prefer communication partners with similar knowledge and values (homophily).

Did ingroup communication have the same effects on knowledge and values as outgroup communication (RQ3)? The answer is negative and, surprisingly, significant positive network autocorrelation occurred more often between members of different stakeholder groups while negative network autocorrelation happened more often between members of the same stakeholder group. If network autocorrelation represents communication effects, this result indicates that stakeholders tended to adopt the knowledge and values of their most frequent communication partners in other stakeholder groups while they tended to move away from those of their ingroup communication partners. Thus, outgroup communication created bridging ties that decreased differences between representatives of stakeholder groups. At the same time, differences between the representative and fellow members within the stakeholder group increased.

An alternative interpretation focusing on selection of communication partners is possible. Stakeholders prefer to communicate with outgroup members who are least different because this is more convenient and less confronting. In addition, they prefer communication with the members of their own group who are most dissimilar because they want to share or validate their new knowledge and values. Note that the second part of this interpretation predicts positive ingroup network autocorrelation at some later time if the efforts to share new knowledge with ingroup members are successful.

Do the effects of communication on knowledge and values depend on the structure of the communication network (RQ4)? Network heterogeneity did not predict the strength or direction of network autocorrelation across management systems, so we cannot conclude that more or less network heterogeneity enhances communication effects. Network centralization had a significant negative predictive effect on network autocorrelation in the case of overall communication and notably ingroup communication. In a more centralized network, stakeholders tended to agree less on knowledge and 
Table 4. Multilevel regression results: unstandardized estimates and standard errors (Model 2). ${ }^{\dagger}$

\begin{tabular}{|c|c|c|c|c|c|c|}
\hline & \multicolumn{2}{|c|}{ Overall } & \multicolumn{2}{|c|}{ Ingroup } & \multicolumn{2}{|c|}{ Outgroup } \\
\hline & $b$ & S.E. & $b$ & S.E. & $b$ & S.E. \\
\hline \multicolumn{7}{|l|}{ Fixed part } \\
\hline Constant & 0.02 & 0.01 & -0.01 & 0.03 & $0.05 * * *$ & 0.02 \\
\hline International & $-0.17 * * *$ & 0.03 & $-0.31 * * *$ & 0.07 & $-0.08 *$ & 0.04 \\
\hline Co-management & -0.03 & 0.02 & -0.02 & 0.04 & $-0.05^{*}$ & 0.02 \\
\hline Network heterogeneity (gm) & 0.14 & 0.08 & 0.22 & 0.18 & -0.03 & 0.10 \\
\hline Network centralization $(\mathrm{gm}) \stackrel{\ddagger}{\ddagger}$ & $-0.41 * *$ & 0.15 & $-0.81^{*}$ & 0.32 & -0.25 & 0.18 \\
\hline \multicolumn{7}{|l|}{ Random part } \\
\hline \multicolumn{7}{|l|}{ Level: management system } \\
\hline Random intercept & 0.00 & 0.00 & 0.00 & 0.00 & 0.00 & 0.00 \\
\hline \multicolumn{7}{|l|}{ Level: statement } \\
\hline Error & $0.01 * * *$ & 0.00 & $0.02 * * *$ & 0.00 & $0.02 * * *$ & 0.00 \\
\hline Units: management system & 6 & & 6 & & 6 & \\
\hline Units: statement & 192 & & 192 & & 192 & \\
\hline
\end{tabular}

$\dagger * p<0.05 . * * p<0.01$. *** $p<0.001$.

$\ddagger(\mathrm{gm})=$ grand-mean centered.

values with their communication partners, especially those from their own stakeholder group.

This result may indicate that communication is part of deliberation rather than information exchange in the systems studied here because centralization was hypothesized to be detrimental to deliberation (Newig et al. 2010), which may result in growing disagreement. The finding that negative network autocorrelation appeared mainly for ingroup communication would then suggest that centralization is particularly detrimental to deliberation within stakeholder groups. From the perspective of tie selection, however, more disagreement in centralized communication networks may be linked to the organization of communication. Perhaps centralization itself results from institutional constraints on who communicates with whom; for example, the management system may be dominated by few actors who are inevitable communication partners due to their power and expertise. If stakeholders have less freedom to select their communication partners, they are more likely to be linked to actors with different knowledge and values.

Finally, the relevance of institutional characteristics to communication effects was tested (RQ5). Among the case studies, management systems spanning different countries had more disagreement among communication partners than did national or regional management systems. It is premature to generalize this result because it was due to just one case study. In addition, systems featuring co-management by stakeholders tended to have significant negative autocorrelation for outgroup communication. Interpreted as a communication effect, higher levels of stakeholder involvement decreased rather than increased agreement on knowledge and values across stakeholder groups. Regarding values, this result could mean that stakeholder groups become more aware of their proper interests due to more intensive and consequential deliberation. Thus, co-management may empower stakeholders with conflicting interests and different knowledge (compare Crona and Bodin 2010). Increasing disagreement on knowledge, however, is hard to understand as a consequence of more intense communication. Here, interpretation from the perspective of tie selection is more plausible: Higher involvement in the management process requires more deliberation with representatives of other stakeholder groups who have different knowledge and values.

\section{CONCLUSION}

Natural resource management systems are designed to facilitate knowledge sharing and adaptation of values among stakeholders. We set out to investigate whether and under which conditions interpersonal communication is relevant to the adaptation of stakeholders' knowledge and values. Six management systems were analyzed, each concerning management of fish stocks and involving some dozens of stakeholders, who were queried on sixteen statements reflecting contested knowledge, on sixteen statements about contested values, and on their most frequent communication ties.

The main result of this study is that stakeholders tended to agree more with communication partners from other stakeholder groups while they tended to disagree more with partners from their own group when we controlled for average differences in knowledge and values between stakeholder groups. If this result reflects effects of interpersonal communication, we may conclude that communication 
Fig. 4. Autocorrelation effects for ingroup and outgroup communication partners (Model 1b).

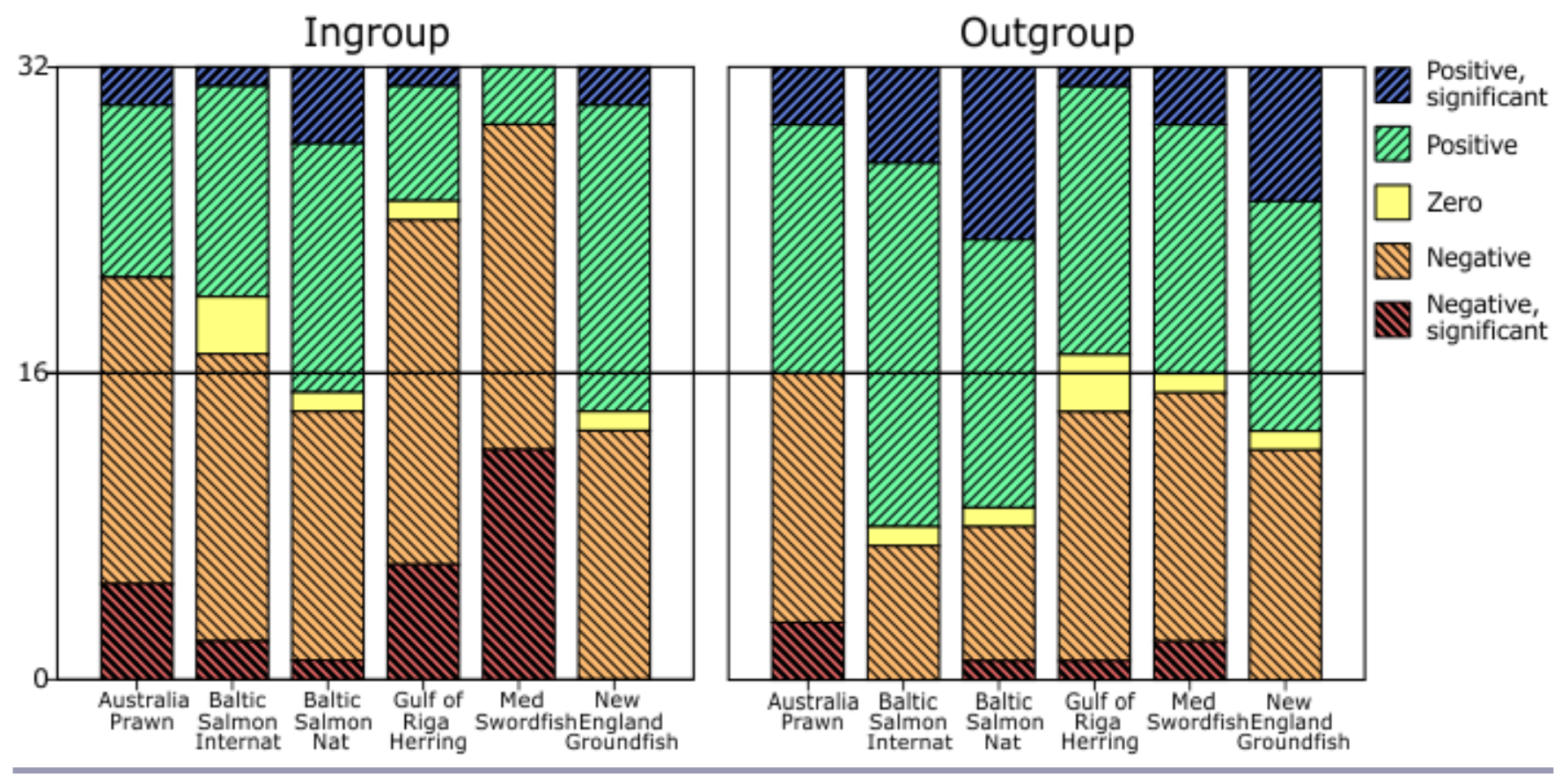

decreases between-group differences and increases withingroup differences. In this view, interpersonal communication mitigates institutional barriers among stakeholder groups. Management efforts directed at establishing, maintaining, or intensifying communication ties among members of different stakeholder types may then be beneficial to consensus formation across stakeholder groups. In addition, management systems with more centralized communication networks tended to have more disagreement among communication partners within stakeholder groups while co-management systems displayed more disagreement between stakeholder groups. Communication effects, if they appear, clearly depend on context.

The results, however, may reveal selection effects instead of communication effects: stakeholders choosing or being assigned communication partners with similar or dissimilar knowledge and values. More disagreement among communication partners in co-management systems may actually reflect success in creating dialogue between stakeholders with different knowledge and values. Tie selection and tie effects are difficult to disentangle conceptually (Shalizi and Thomas 2011); they probably appear concurrently. Over time, tie selection and tie effects constitute a dynamic system in which stakeholders' opinions co-evolve with the structure of the communication network.

Further research should investigate the co-evolution of opinions and network structure. For this purpose, longitudinal data are needed both on the communication network and on stakeholders' knowledge and values. Statistical techniques are available to model the co-evolution in panel data (Snijders et al. 2010) while event history models can be used for continuous-time data (e.g., Butts 2008, Brandes et al. 2009, de Nooy 2011). Data may be collected by means of surveys, content analysis of documents (minutes, e-mail correspondence), and participant observation.

For the study of natural resource management, this opens the possibility to study the interplay between different network relations. For example, does information exchange promote trust between stakeholders and vice versa, and does this foster support for each other's positions and proposals during decision-making? More specific information on communication and other ties should be included, at a minimum addressing whether the tie arose from personal choice or institutional arrangements. Finally, stakeholder category should not be the only actor characteristic in the model. Psychological features such as cognitive entrenchment (Dane 2010) will likely affect how stakeholders respond to management efforts while professional characteristics such as expertise and authority are relevant to both the creation or maintenance of ties and the adoption of knowledge and opinions by peers.

The results of the present study draw our attention to another way in which time is important. Perhaps positive and negative communication network effects occur at different phases in the process of managing an issue. Imagine a situation with 
stakeholder groups that have different positions on an issue and let us assume that interpersonal communication reduces these differences. Initially, communication among representatives of different stakeholder groups results in increasing agreement among the representatives. In this first phase, positive outgroup communication effects appear. However, representatives move away from the average knowledge and values that characterize their own stakeholder group, increasing disagreement within their own stakeholder groups. This triggers efforts on the part of the representatives to convince stakeholders within their groups, e.g., first selecting communication partners among group members with most dissimilar opinions (yielding stronger negative ingroup communication effects) and convincing them to change their opinions (positive ingroup communication effects) in a next phase. This illustrates that context as well as time are crucial for understanding and managing the effects of communication among stakeholders.

Responses to this article can be read online at: http://www.ecologyandsociety.org/issues/responses. $\mathrm{php} / 5648$

\section{Acknowledgments:}

The data were collected and analyzed for the JAKFISH (Judgement and Knowledge in Fisheries Involving Stakeholders) project, which was financed by the European Union in the context of the Seventh Framework Programme, Theme 2: Food, Agriculture and Fisheries, and Biotechnology, Grant Number 212969. The author is grateful for the comments and suggestions provided by three anonymous reviewers and the journal's editor, Lance Gunderson, which were very helpful in improving the paper.

\section{LITERATURE CITED}

Allport G. W. 1954. The nature of prejudice. Addison-Wesley Publishing Company, Cambridge, Massachusetts, USA.

Andersson K. 2006. Understanding decentralized forest governance: an application of the institutional analysis and development framework. Sustainability: Science, Practice, \& Policy 2(2):25-35.

Axelrod R. A. 1984. The evolution of cooperation. Basic Books, New York, New York, USA. http://dx.doi. org/10.1126/science.7466396

Blumenthal, D. and J. L. Jannink. 2000. A classification of collaborative management methods. Conservation Ecology 4 (2): 13. [online] URL: http://www.consecol.org/vol4/iss $2 /$ art13/" target="new".

Bodin Ö., B. Crona, and H. Ernstson. 2006. Social networks in natural resource management: What is there to learn from a structural perspective? Ecology and Society 11(2): r2. [online] URL: http://www.ecologyandsociety.org/vol11/iss2/ resp2/.

Bodin Ö., and C. Prell. 2011. Social networks and natural resource management: uncovering the social fabric of environmental governance. Cambridge University Press, Cambridge, UK. http://dx.doi.org/10.1017/CBO9780511894985

Borgatti S. P., and P. C. Foster. 2003. The network paradigm in organizational research: a review and typology. Journal of Management 29(6):991-1013.

Brandes, U., J. Lerner, and T. A. B. Snijders. 2009. Networks evolving step by step: statistical analysis of dyadic event data. Pages 200-205 in N. Memon, and R. Alhajj, editors. ASONAM 2009, 2009 International Conference on Advances in Social Network Analysis and Mining. IEEE Computer Society, Washington D.C., USA. http://dx.doi.org/10.1109/ASONAM.2009.28

Brown S. R. 1986. Q technique and method: principles and procedures. Pages 57-76 in W. D. Berry and M. S. LewisBeck, editors. New tools for social scientists, Sage, Beverly Hills, California, USA.

Brown S. R. 1993. A primer on Q methodology. Operant Subjectivity 16(3/4):91-138.

Butts C. T. 2006. The sna package: tools for social network analysis, V2.2. Department of Sociology, University of California, Irvine, California, USA.

Butts C. T. 2008. A relational event framework for social action. Sociological Methodology 38(1):155-200. http://dx. doi.org/10.1111/j.1467-9531.2008.00203.x

Chang C., J. C. Allen, S. E. Dawson, and G. E. Madsen. 2012. Network analysis as a method for understanding the dynamics of natural resource management in rural communities. Society \& Natural Resources 25(2):203-208. http://dx.doi. org/10.1080/08941920.2011.571753

Crona, B., and Ö. Bodin. 2006. What you know is who you know? Communication patterns among resource users as a prerequisite for co-management. Ecology and Society 11(2): 7. [online] URL: http://www.ecologyandsociety.org/vol11/ iss $2 / \operatorname{art} 7 /$.

Crona, B., and Ö. Bodin. 2010. Power asymmetries in smallscale fisheries: a barrier to governance transformability? Ecology and Society 15(4): 32. [online] URL: http://www. ecologyandsociety.org/vol15/iss4/art32/.

Crona, B., and K. Hubacek. 2010. The right connections: how do social networks lubricate the machinery of natural resource governance? Ecology and Society 15(4): 18 [online] URL: http://www.ecologyandsociety.org/vol15/iss4/art18/

Dane E. 2010. Reconsidering the trade-off between expertise 
and flexibility: a cognitive entrenchment perspective. Academy of Management Review 35(4):579-603. http://dx. doi.org/10.5465/AMR.2010.53502832

Degnbol P., H. Gislason, S. Hanna, S. Jentoft, J. Raakjær Nielsen, S. Sverdrup-Jensen, and D. Clyde Wilson. 2006. Painting the floor with a hammer: technical fixes in fisheries management. Marine Policy 30(5):534-543. http://dx.doi. org/10.1016/j.marpol.2005.07.002

de Nooy W. 2011. Networks of action and events over time: a multilevel discrete-time event history model for longitudinal network data. Social Networks 33(1):31-40. http://dx.doi. org/10.1016/j.socnet.2010.09.003

de Nooy W., A. Mrvar, and V. Batagelj. 2011. Exploratory social network analysis with Pajek. Revised and Expanded Second Edition. Cambridge University Press, Cambridge, UK.

Doreian P. 1980. Linear models with spatially distributed data: spatial disturbances or spatial effects? Sociological Methods and Research 9(1):29-60.

Dreyer M., and O. Renn. 2011. Participatory approaches to modelling for improved learning and decision-making in natural resource governance: an editorial. Environmental Policy and Governance 21(6):379-385. http://dx.doi. org/10.1002/eet.584

Festinger L. 1954. A theory of social comparison processes. Human Relations 7(2):117-140. http://dx.doi.org/10.1177/0$\underline{01872675400700202}$

Festinger L. 1957. A theory of cognitive dissonance. Tavistock, London, UK.

Friedkin N. E. 1998. A structural theory of social influence. Cambridge University Press, Cambridge, UK. http://dx.doi. org/10.1017/CBO9780511527524

Friedkin N. E., and E. C. Johnsen. 1990. Social influence and opinions. Journal of Mathematical Sociology 15 (3-4):193-205. http://dx.doi.org/10.1080/0022250X.1990.9990069

Goldsborough, D., L. Berner, P. Haapasaari, T. Johnson, D. C. Wilson, and M. A. Pastoors. 2011. A socialnetwork analysis of a marine management science-policy community for six case studies. JAKFISH Deliverable 5.1, 144 p. Judgement and Knowledge in Fisheries Involving Stakeholders (JAKFISH), Seventh Framework Programme, Theme 2: Food, Agriculture and Fisheries, and Biotechnology, European Union.

Jentoft S., B. J. McCay, and D. C. Wilson. 1998. Social theory and fisheries co-management. Marine Policy 22(4-5):423-436. http://dx.doi.org/10.1016/S0308-597X(97)00040-7
Leenders R. T. A. J. 2002. Modeling social influence through network autocorrelation: constructing the weight matrix. Social Networks 24(1):21-47. http://dx.doi.org/10.1016/ S0378-8733(01)00049-1

Mackinson S., D. C. Wilson, P. Galiay, and B. Deas. 2011. Engaging stakeholders in fisheries and marine research. Marine Policy 35(1):18-24. http://dx.doi.org/10.1016/j. marpol.2010.07.003

McPherson M., L. Smith-Lovin, and J. M. Cook. 2001. Birds of a feather: homophily in social networks. Annual Review of Sociology 27(1):415-444. http://dx.doi.org/10.1146/annurev. soc.27.1.415

Mizruchi M. S., and E. J. Neuman. 2008. The effect of density on the level of bias in the network autocorrelation model. Social Networks 30(3):190-200. http://dx.doi.org/10.1016/j. socnet.2008.02.002

Monge P. R., and N. S. Contractor. 2003. Theories of communication networks. Oxford University Press, New York, New York, USA.

Mushove P., and C. Vogel. 2005. Heads or tails? Stakeholder analysis as a tool for conservation area management. Global Environmental Change 15(3):184-198. http://dx.doi.org/10.1016/ j.gloenvcha.2004.12.008

Newig, J., D. Günther, and C. Pahl-Wostl. 2010. Synapses in the network: learning in governance networks in the context of environmental management. Ecology and Society 15(4): 24. [online] URL: http://www.ecologyandsociety.org/vol15/ iss 4/art24/

Newman, L. L., and A. Dale. 2005. Network structure, diversity, and proactive resilience building: a response to Tompkins and Adger. Ecology and Society 10(1): r2. [online] URL: http://www.ecologyandsociety.org/vol10/iss1/resp2/.

Newman L., and A. Dale. 2007. Homophily and agency: creating effective sustainable development networks. Environment, Development and Sustainability 9(1):79-90. http://dx.doi.org/10.1007/s10668-005-9004-5

Ostrom E. 1990. Governing the commons : the evolution of institutions for collective action. Cambridge University Press, Cambridge, UK. http://dx.doi.org/10.1017/CBO9780511807763

Pastoors, M. A., C. M. Ulrich, D. C. Wilson, C. Röckmann, D. Goldsborough, D. Degnbol, L. Berner, T. Johnson, P. Haapasaari, M. Dreyer, E. Bell , E. Borodzicz, K. Hiis Hauge, D. Howell, S. Mäntyniemi, D. Miller, R. Aps, G. Tserpes, S. Kuikka, and J. Casey. 2012. Policy brief: institutions, practices and tools to address complexity, uncertainty and ambiguity in participatory fisheries management. An attempt 
to redefine the institutional role of science in EU fisheries policies. JAKFISH Deliverable 6.2, 18 p. Judgement and Knowledge in Fisheries Involving Stakeholders (JAKFISH), Seventh Framework Programme, Theme 2: Food, Agriculture and Fisheries, and Biotechnology, European Union.

Prell C., K. Hubacek, and M. Reed. 2009. Stakeholder analysis and social network analysis in natural resource management. Society \& Natural Resources 22(6):501-518. http://dx.doi. org/10.1080/08941920802199202

Prell, C., M. Reed, L. Racin, and K. Hubacek. 2010. Competing structure, competing views: the role of formal and informal social structures in shaping stakeholder perceptions. Ecology and Society 15(4): 34. [online] URL: http://www. ecologyandsociety.org/vol15/iss4/art34/.

Rasbash J., F. Steele, W. Browne, and B. Prosser. 2004. A user's guide to MLwiN, Version 2.0. Centre for Multilevel Modelling, London, UK.

Robins G. L., P. Elliott, and P. Pattison. 2001. Network models for social selection processes. Social Networks 23(1):1-30. http://dx.doi.org/10.1016/S0378-8733(01)00029-6

Röckmann C., C. Ulrich, M. Dreyer, E. Bell, E. Borodzicz, P. Haapasaari, K. H. Hauge, D. Howell, S. Mäntyniemi, D. Miller, G. Tserpes, and M. Pastoors. 2012. The added value of participatory modelling in fisheries management-what has been learnt? Marine Policy 36(5):1072-1085.

Sandström, A., and C. Rova. 2010. Adaptive co-management networks: a comparative analysis of two fishery conservation areas in Sweden. Ecology and Society 15(3): 14. [online] URL: http://www.ecologyandsociety.org/vol15/iss3/art14/.

Schneider M., J. Scholz, M. Lubell, D. Mindruta, and M. Edwardsen. 2003. Building consensual institutions: networks and the National Estuary Program. American Journal of Political Science 47(1):143-158. http://dx.doi. org/10.1111/1540-5907.00010

Shalizi C. R., and A. C. Thomas. 2011. Homophily and contagion are generically confounded in observational social network studies. Sociological Methods \& Research 40 (2):211-239. http://dx.doi.org/10.1177/0049124111404820

Snijders T. A. B., G. G. van de Bunt, and C. E. G. Steglich. 2010. Introduction to stochastic actor-based models for network dynamics. Social Networks 32(1):44-60. http://dx. doi.org/10.1016/j.socnet.2009.02.004

Suls J., R. Martin, and L. Wheeler. 2002. Social comparison: why, with whom and with what effect? Current Directions in Psychological Science 11(5):159-163.
Tompkins, E. L. and W. N. Adger. 2004. Does adaptive management of natural resources enhance resilience to climate change? Ecology and Society 9(2): 10. [online] URL: http:// www.ecologyandsociety.org/vol9/iss2/art10/.

Wasserman S., and K. Faust. 1994. Social network analysis: methods and applications. Cambridge University Press, Cambridge, UK. http://dx.doi.org/10.1017/CBO9780511815478 